\title{
Eğitim Örgütleri İçin Lidere Güven Ölçeğinin Geliştirilmesi: Geçerlik ve Güvenirlik Çalışması ${ }^{1}$
}

DOI: $10.26466 /$ opus. 861588

\author{
* \\ Gamze Tuti ${ }^{*}$ - Murat Özdemir ** \\ * Dr, Öğretmen, Milli Eğitim Bakanlı̆̆ı, Trabzon/Türkiye \\ E-Posta: gmzeclskn@gmail.com \\ ORCID: $0000-0001-8831-6613$ \\ ** Prof.Dr, Hacettepe Üniversitesi Eğitim Fakültesi, Ankara/Türkiye \\ E-Posta: $\underline{\text { mrtozdem@hacettepe.edu.tr } \quad \text { ORCID: 0000-0002-1166-6831 }}$
}

Öz

Bu çalışmada öğretmen görüşlerine göre öğretmenlerin lidere güven davranışların belirlemeye elverişli, geçerli ve güvenilir bir ölçeğin geliştirilmesi amaçlanmıştır. Bu kapsamda lidere güvene ilişkin literatüre dayal olarak hazırlanan madde havuzu için, uzman görüşüne başvurulmuştur. Uzmanlardan gelen öneriler ışı̆̆ında 20 maddelik taslak ölçek oluşturulmuştur. Ölçeğin ilk aşaması, Trabzon ilindeki okullarda görev yapan 159 öğretmene uygulanmıştır. Verilerin Açımlayıcı faktör analizi (AFA) için gerekli varsayımları sağlayıp sağlamadığını tespit edebilmek amacıyla KaiserMeyer-Olkin ve Bartlett Küresellik testi uygulanmıştır. AFA ile ölçeğin yapı geçerliği incelenmiştir. Ölçeğin İkinci aşamasında, Trabzon ilindeki farkl 178 öğretmene doğrulayıcı faktör analizi uygulanmıştır. AFA ile Lidere Güven Ölçeğinin (LGÖ) tek faktörlü olduğu ortaya konulmuştur. LGÖ, varyansın \%73'ünü açılamıştır. DFA analizleri tek faktörlü modele ilişkin bulguların uyum iyiliği değerlerinin "mükemmel uyum" düzeyinde olduğunu göstermiştir. LGÖ'de yer alan madde ve faktörlerin ayırt edicilik güçlerinin de yüksek olduğu belirlenmiştir. Bu sonuçlar da LGÖ'nün yüksek düzeyde güvenilir olduğunu göstermiştir. Bu bulgulara dayal olarak, LGÖ'nün Türkiye'deki okullarda öğretmenlerin lidere güven davranışlarını belirlemede kullanılmaya elverişli, geçerli ve güvenilir bir veri toplama aracı olduğu sonucuna ulaşılmıştır.

Anahtar Kelimeler: Eğitim Yönetimi, Liderlik, Lidere güven, Geçerlik, Güvenirlik.

\footnotetext{
${ }^{1}$ Bu çalışma 1. yazarın doktora tezinden üretilmiştir.
} 
ISSN:2528-9527

E-ISSN: 2528-9535

YIl Year: 11

Cilt Volume: 18

Sayı Issue: Eğitim Bilimleri Özel Sayısı

Eylül September 2021

Uluslararası Toplum Araştırmaları Dergisi

International Journal of Society Researches

Makalenin Geliş Tarihi Received Date: 15/01/2021

Makalenin Kabul Tarihi Accepted Date: 03/06/2021

\title{
Trust in Leaders Scale Development for Educational Organizations: A Validity and Reliability Study
}

*

\begin{abstract}
In this study, development of a valid and reliable scale that is suitable for determining teachers' behaviors of trust in the leader according to teachers' views was aimed. In this context, expert opinion was consulted for the item pool prepared based on the literature on trust in the leader. A draft scale with 20 items was created in the light of the suggestions of experts. The first stage of the scale was applied to 159 teachers working at schools in Trabzon province. Kaiser-Meyer-Olkin and Bartlett Sphericity tests were administered to determine whether the data provided the necessary assumptions for Exploratory Factor Analysis (EFA). The construct validity of the scale was examined with EFA. At the second stage of the scale, the Confirmatory Factor Analysis (CFA) was applied to 178 different teachers in Trabzon. It has been revealed with EFA that Trust in Leaders Scale (TLS) has a single factor. TLS explained $73 \%$ of the variance. CFA analysis showed that the goodness of fit values of the findings related to the single factor model were at the "perfect fit" level. It has been determined that the discrimination power of the items and factors in the TLS is also high. These results also showed that TLS is highly reliable. Based on these findings, TLS is concluded to be a valid and reliable data collection tool suitable for use in determining the trust in leaders behavior of teachers at schools in Turkey.
\end{abstract}

Key Words: Educational Management, Leadership, Trust in Leader, Validity, Reliability. 


\section{Giriş}

Geçmişten günümüze kadar yöneticilerin liderlik tarzları örgütsel başarı ya da başarısızlık için bir kriter olmuş ve birçok farklı değişkenle ilişkisi araştırılmıştır. Eğitim örgütleri açısından bu çalışmalara bakıldığında okul müdürlerinin liderlik davranışları ile öğretmenlerin motivasyon (Ugar, 2019), örgütsel bağlllık (Ertürk, 2019), iş doyumu (Karadağ, Başaran ve Korkmaz, 2009), psikolojik sermaye (Bilgiç, 2020), örgütsel güven (Cemaloğlu ve Kılınç, 2012), örgütsel sosyalleşme (Erden, 2007), mesleki tükenmişlik (Özcan, 2019), okul iklimi (Ertuğrul ve Töremen, 2017), öğrenci başarısı (Yılmaz Fındık ve Kavak,2016) ve adanmışlık (Atar, 2009) düzeyleri arasında anlamlı ilişkiler tespit edildiği görülmüştür. Örgütlerde motivasyonun az olması, mesleki tükenmişlik yaşanması ve iletişim gibi sorunlarının temel sebeplerinden birisi örgütsel güven düzeyindeki düşüklük ile açklanmıştır. Ancak liderlik alanında yapılan çalışmalarda güven değişkeni ile ilgili az sayıda araştırma bulunduğu gözlemlenmiştir (Cemaloğlu ve Kılınç, 2012; Korkmaz, 2017; Yolaç, 2011). Halbuki güven, liderliğin en temel bileşenlerinden birisidir (Bennis, 1995). Eraslan'a (2004) göre, etkin bir liderin, astlarının güvenini kazanmak için söyledikleriyle ve davranışlarıyla tutarlı olması beklenir. Eğitim örgütleri açısından lidere güven öğretmenlerin okullarında lider olan yöneticilerine karşı güven olgusuna ilişkin algılarını ifade etmektedir. Liderin, güven tabanlı bir çalışma ortamı oluşturma çabasının örgütsel etkililiğin yükselmesinde en önemli unsurlardan biri olduğunun ortaya konması (Kovač ve Jesenko, 2010) bu önemi desteklemektedir.

Güven olgusunun tarihsel geçmişine bakıldığında; 1950'li yıllarda soğuk savaşla ortaya çıkan şüpheci yaklaşımın ürünü olan "güven" sosyal bilimciler için bir araştırma alanı olmuştur. 1960'larda otoriteye olan şüpheci yaklaşımının artan etkisiyle kişisel bir kimlik haline büründürülmüştür. 1980'lerin ilk yıllarında ise Amerika'da boşanma gibi değişen aile yapılarından etkilenerek kişiler arası ilişkiler açısından önemli bir boyut kazanmıştır. 1990'lardaki teknolojik küresel değişimin bir sonucu olarak güven kavramı toplumsal düzeyde yeniden ekonomi, örgüt ve sosyoloji biliminin konusu haline gelmiştir (Hoy ve TschannenMoran, 1999). Tarihsel süreçte birçok boyut kazanan güven olgusu, 
herkes tarafından bilinmekte olup tanımlanması karmaşık ve zor bir kavramdır. Bu karmaşıklık durumdan duruma ve farklı ilişkilere göre değişiklik göstermektedir. Bu nedenle literatürde güven kavramına yönelik birçok tanıma rastlanmaktadır. Birçok tanımda (Baier, 1985; Holmes ve Rempel, 1989; Hoy ve Tschannen-Moran, 1999) güven kavramı farklılık gösterse de bireyin diğer bireylere karşı beklenti ve savunmasızlık hali ifadesinin ortak görüş olarak vurgulandığını söylemek mümkündür. Hoy ve Tschannen-Moran (1999) bu ortak ifadesini esas alarak güvenin çeşitli boyutlardan oluşan karmaşık bir kavram olduğunu ifade etmişlerdir. Bu boyutları; (i) risk alma istekliliğ̈i, (ii) iyilikseverlik, (iii) itimat, (iv) yetkinlik, (v) dürüstlük ve (vi) açıklık olarak açıklamışlardır. Risk alma istekliliği, bireyin diğer bireylere karşı savunmasızlık halini ifade etmektedir. İyilikseverlik, bireyin kendi iyi olma durumunun güvendiği kişilerce korunmasından emin olma durumudur. Diğer güven unsuru olan itimat, bir hedef doğrultusunda bireyin başkalarına karşı duymuş olduğu beklenti seviyesidir. Güven için iyi niyet yanında bireyin beklenti içerisinde olduğu durumların karşılanması için çeşitli yetenekler gerekebilir. Bu yetenekler güvenin yetkinlik boyutunu ifade eder. Güven için önemli olan unsurlardan diğerleri doğruluk ifadesini karşılayan dürüstlüktür ve bilginin saklı kalması ve diğer bireylerle paylaşılma derecesini ifade eden açıklıktır. Bu konuda örgütler için güvenin önemli olduğunu savunan birçok araştırma da mevcuttur (Asunakutlu, 2002; Demircan ve Ceylan, 2003; Polat, 2007; Tschannen-Moran ve Hoy, 1998).

Örgütlerde zaman içerisinde meydana gelen ilişki ağlarındaki çeşitlilik ve değişim güven unsurunun öneminin daha da artmasına neden olmuştur. Örgütlerde kişilerin yöneticilerine ve diğer paydaşlara olan güvenin örgüt performansı ve etkinliği için vazgeçilmez bir unsur olduğu ifade edilmektedir (Asunakutlu, 2002; Tschannen-Moran ve Hoy,1998). Örgütsel güven olarak ifade edilen bu kavram, çalışanın örgütüne, liderin dürüstlügüne ve verdiği sözü yerine getireceğine olan inancıdır. (Demircan ve Ceylan, 2003). Örgütsel güven kavramının çok boyutluluğu ile ilgili çalışmalar Hoy ve Kupersmith'in (1985) Güven Ölçeği (GÖ) çalışması ile başlamıştır. Daha sonra Hoy ve TschannenMoran (1999) tarafından güven kavramı; yöneticiye güven, meslektaşlara 
güven ve veli-öğrencilere ilişkin güven olarak üç alt boyutta toplanarak kavramsallaştırılmıştır. (Erden, 2007).

Yöneticiye güven; bireyin örgütte güveni meydana getirecek olan okul yöneticilerine güvenini ifade etmektedir. Meslektaşlara güven; çalışma arkadaşlarına olan güvenini tanımlamaktadır. Veli-öğrenciye olan güven ise okulun önemli paydaşlarından olan öğrenci ve velilerine olan güveni açılamaktadır. Eğitim örgütleri olan okullarda sürdürülebilir bir örgütsel güven ortamının oluşturulmasında en büyük sorumluluğun yöneticilere ait olduğu söylenebilir. Okul yöneticilerinin, okuldaki güven ortamında etkileşimi sağlamak için gösterecekleri liderlik tarzları önem arz etmektedir. Yapılan bir çalışmada güven temelli örgütlerdeki bireylerin iş yönelimlerinin pozitif etkilendiği ayrıca lider durumundaki yöneticiye olan güvenin çalışanlar arasında etkileşimi ve iş doyumlarını artırdığı ifade edilmiştir (Driscoll, 1978; Pillai, Schriesheim ve Williams, 1999). Diğer bir çalışmaya göre de, örgütsel güven oluşmasında etkili boyutlardan biri olan yöneticiye güvenin, çalışanların iş doyumu üzerinde etkili olduğu vurgulanmıştır (Koç ve Yazıcıŏ̆lu, 2011). Bu çalışmalar okul yöneticilerinin lidere duyulan güven açısından, çalışma ortamında daha etkin olabilmesi ve çalışanların kendisine olan bağlılık duygusunun gelişmesi için önemli bir faktör olduğu düşüncesini desteklemektedir. Yöneticiye veya lidere güven, çalışanların, liderin dürüst, adaletli, etik ve tutarlı davranacağına dair olan inançlarıdır (Özdaşlı ve Yücel, 2010). Bireyler örgüt liderlerine güven duyunca, örgütte yer alan kurallara uyarak örgütsel değişime destek olacak performanslarını ve motivasyonlarını arttıracaklardır (Robinson, 1996).

Liderler ile çalışanları arasında güven duygusunun geliştirilmesi aşamasında liderin yönetsel davranışları etkin rol oynamaktadır. Whitener ve arkadaşlarına (1998) göre çalışanların, yönetsel güvene yönelik algısında, liderinin beş etkili davranışı bulunmaktadır. Bunlar; (i) etkin iletişim, (ii) saygın davranış, (iii) ilgili davranma, (iv) tutarlı davranış, (v) denetimi dağıtma ve paylaşmadır. Butler ve Cantrell (1984) ise benzer bir görüşle bu davranışların lider ve çalışan ilişkilerinde konuma göre farklılık oluşturabileceğini söylemiştir. Buna göre beş öğe şu şekilde açıklamıştır; (i) dürüstlük, güven duyulan kişinin güvenilirlik ve dürüstlük doğrultusunda oluşan şöhret, (ii) yeterlik, görevi 
gerçekleştirmek için ihtiyaç olan bilgi ve deneyim, (iii) tutarlılık, doğru yargı, güvenilirlik, kestirilebilirlik, (iv) sadakat, teşvik etme, diğer tarafları destekleme, yardımseverlik arzusu, (v) açıklık, bilgi, beceri ve fikirlerini açık bir şekilde özgürce diğer örgüt üyeleri ile paylaşma arzusu.

Butler (1991) başka bir çalışmasında "güvenin koşulları" konusunu ele almış ve lider yöneticinin özelliklerini çalışanların liderlerine karşı duydukları güven, tutarlı ve dürüst davranışlar olarak ifade etmiştir. Lider ve çalışanlar arasındaki etkileşim, örgütlerin varoluş temelleri için önemli etkenlerden birisi olduğu söylenebilir. Bu etkileşim sayesinde örgüt amaçları doğrultusunda varlığını sürdürürken; örgüt çalışanları ise liderine duyduğu güveni genelleştirerek bütün örgüte karşı bir güven duygusu oluşturacaklardır. Yani örgütsel anlamda güvenin ilk basamağının, örgüt liderinin hal ve hareketleri olduğu ifade edilebilir. Whitener ve arkadaşları (1998), örgüt yönetimine duyulan güveni, örgüt yöneticilerinin gösterdikleri davranışlar ile ilişkilendirmiş ve bu konuyla ilgili, üç kişisel unsur belirlemiştir; (i) değerler, (ii) güvene eğilim ve (iii) öz verimlilik. Örgüt liderlerinin güvene ilişkin eğilimleri, bilgi, ustalık, yetenek derecelerindeki öz verimlilikleri, beğenilme, anlayışlı davranarak diğer çalışanların haklarını sahip çıkma ve evrensel değerlere saygı davranışları örgütte güven ortamı oluşturulmasında olumlu etki yaratan tutumlardır. Tan ve Tan (2000), örgüt liderine güveni ise liderin yardımseverliği, yeteneği, saygınlığı gibi değişken davranışlar ile açıklamıştır. Bu duruma göre, örgüt çalışanının, örgüte ve örgüt liderine duyulan güvene bağlı olarak, farklı davranışlar sergileyebildiği belirtilmiştir. Örgüte duyulan güven, örgütsel bağlllıkta düşük devir hızı eğilimini etkilerken, örgüt liderine güvenin, çalışanların memnuniyetini, performansını tetiklediği görülmüştür (Tan ve Tan 2000).

Lider okul yöneticileri için Greenfield (1991) öğretmenler üzerinde etki oluşturan, kendisi ve işi hakkında olumlu bakış açısına sahip ve yapılan her türlü işle ilgili hedeflerin gerçekleştirme sürecinde onlara yardımcı olan kişi olarak ifade etmektedir (Çelik, 2003). Dolayısıyla eğitim yöneticisi konumunda bulunan kişiler de bağlı bulundukları kurumları en verimli şekilde işler duruma getirebilmek ve hedefe ulaştırabilmek için liderlik yapmaları beklenir. Eğitim kurumu 
yöneticilerinin liderlik davranışları öğretmenlerin tutumlarını etkileyeceğinden (Cemaloğlu, 2007) günümüz şartlarında klasik yönetim ile çok fazla başarı elde edemeyecek yöneticiler yerine, organize olmuş gruplar ile birlikte hareket edebilen ve onları başarı hedefi ile yönlendirebilen liderler ön plana çıkmaya başlamıştır. İnsan ilişkilerinin yoğun olarak yaşandığı okullarda tüm bireyleri hedefler etrafında toplayarak, ortak hedefleri konusunda güdülenmiş grubun davranışlarını etkileyebilecek yetilere sahip okul yöneticilerine duyulan ihtiyaç giderek artmaktadır (Gümüşeli, 2001). Bu ihtiyaç bağlamında değerlendirildiğinde ise lider olan okul yöneticilerinin önemi daha iyi anlaşılmaktadır.

Eğitim yönetimi alanında liderlik ve güven konuları hala çok fazla ilgi duyulan araştırma alanları olarak karşımıza çıkmaktadır (Boyacı, Karacabey ve Bozkuş, 2018; Bozkurt, Çoban ve Çolakoğlu, 2018; Cansoy ve Parlar, 2018; Dede, 2019; Duman, 2018; Ertürk, 2019; Güven, 2017; Korkmaz, 2017; Uslu, Özsoy ve Ardıç, 2018). Bu süreçte yürütülen çalışmalarda; çalışanların lidere ve yönetime güven duymasının örgüt açısından psikolojik güçlendirme, örgütsel adalet, iş tatmini, örgütsel vatandaşlık, çalışan performansı, işe tutkunluk ve örgüte bağlılık gibi birçok değişken açısından olumlu katkıları olduğu ortaya konmuştur (Demirtaş ve Demirbilek, 2019; Duman, 2018; Hoy ve Tarter, 2004; Hubbell ve Chory-Assad, 2005; Mirza ve Redzuan, 2012; Paşa, 2015; Perry ve Mankin, 2007). Ancak alanyazın incelemelerinde örgütsel güven çalışmaları çok fazla olsa da örgütsel güvenin bir alt boyutu olan yöneticiye veya lidere güven ile ilgili araştırmalara az sayıda çalışmaya rastlanmıştır (Koç ve Yazıcıŏ̆lu, 2011; Demirtaş ve Demirbilek, 2019; Duman, 2018; Ertürk, 2019; Paşa, 2015; Özdaşlı ve Yücel, 2010; Yılmaz, 2019). Bu doğrultuda yapılan çalışmalarda kullanılan ölçeklere bakıldığında öğretmenlerin yöneticilerine karşı duydukları güveni ölçmek için Tschannen-Moran (2003) tarafından geliştirilen, Yılmaz (2006) tarafından geçerlik ve güvenirlik çalışması yapılan Güven Ölçeği'nin alt boyutu olan 7 maddelik Yöneticiye Güven Ölçeği ve Rich'in (1997) pazarlama yöneticileri için geliştirmiş olduğu Lidere Güven Ölçeğinin kullanıldığı görülmüştür. Ancak öğretmenlerin lider olan okul yöneticilerinin güven algılarını saptamak üzere geliştirilmiş güvenilir ve geçerli bir ölçme aracına literatürde rastlanılmamıştır. LGÖ 
ile alandaki ihtiyaç duyulan bu eksikliğe önemli katkılar sunulacağı düşünülmektedir. Literatürdeki bu boşluktan hareketle araştırmanın amac1, öğretmen görüşlerine göre “Lidere Güven Ölçeği'nin (LGÖ) geliştirilmesi kapsamında güvenirlik ve geçerlik analizlerini gerçekleştirmektir. Bu amaç doğrultusunda şu araştırma problemlerine cevap aranmıştır;

1. LGÖ, öğretmenlerin lidere güven davranışlarını tespit etmeye uygun ve geçerli bir veri toplama aracı midır?

2. LGÖ, güvenilir bir veri toplama aracı mıdır?

\section{Yöntem}

\section{Ölçek Geliştirme Süreci}

$\mathrm{Bu}$ araştırmada öğretmen algısına göre "Lidere Güven Ölçeği-LGÖ” geliştirilmesi amaçlanmıştır. $\mathrm{Bu}$ amaç doğrultusunda araştırma için öğretmenlere açık uçlu sorular sorulmuş ve lider olan okul müdürünü ifade eden ve öne çıkan temel unsurlar göz önünde bulundurularak betimlemeleri istenmiştir. Toplanan cevaplar ile literatürdeki benzer çalışmalardan faydalanılarak 56 maddelik bir taslak soru/madde havuzu oluşturulmuştur (Börü, İslamoğlu ve Birsel, 2007; Rich, 1997; TschannenMoran ve Hoy, 1998; Yılmaz, 2006). Bu maddeler lider olan okul müdürünün özelliklerini belirlemeye yönelik olacak şekilde oluşturulmuştur. Taslak form kapsam geçerliliği ve dilsel açıdan değerlendirilmek üzere, eğitim yönetimi alanından toplam yedi uzmanın görüşüne sunulmuştur. Uzman önerileri doğrultusunda 20 maddelik taslak form oluşturulmuş ve lidere güven ölçeği uygulamaya hazır hale getirilmiştir. LGÖ'ye ait likert tipi sorular; Hiç Katılmıyorum (1), Az Katıliyorum (2), Katılıyorum (3), Çok Katıliyorum (4) ve Tamamen Katıllyorum (5) şeklinde derecelendirilmiştir.

\section{Katılımcılar}

Araştırma kapsamında iki farklı çalışma grubundan ardışık olarak veri toplanmıştır. Katılımcılar kolay ulaşılabilir durum örneklemesi (convenience sampling) ile seçilmiştir. Bu örneklem türü araştırmacının 
kolayca ulaşabileceği örneklemdir. Veri toplama sürecine ölçüt olarak katılımclardan mevcut okul müdürleriyle en az bir yıl çalışmış olma şartı belirlenmiştir. Mevcut okul müdürleriyle bir yıldan az çalışan öğretmenlerin verileri analize dahil edilmemiştir. Değişkenler bağlamında katılımcılara ilişkin sayısal veriler Tablo 1'de sunulmuştur.

\section{Tablo 1. Değişkenler Bağlamında Katılımcılara Ait Sayısal Veriler}

\begin{tabular}{lllll} 
Katılımcılara Ait Değişkenler & \multicolumn{2}{l}{$\begin{array}{l}\text { Birinci Çalışma Grubu } \\
\text { (159 Öğretmen) }\end{array}$} & \multicolumn{2}{l}{$\begin{array}{l}\text { İkinci Çalışma Grubu } \\
\text { (178 Ögretmen) }\end{array}$} \\
\hline Cinsiyet & Kadın & 104 & Kadın & 100 \\
& Erkek & 55 & Erkek & 78 \\
\hline Yaş & $20-30$ & 27 & $20-30$ & 32 \\
& $31-40$ & 104 & $31-40$ & 98 \\
& $41-50$ & 23 & $41-50$ & 35 \\
& 50 ve üzeri & 5 & 50 ve üzeri & 13 \\
\hline Eğitim Durumu & Lisans & 133 & Lisans & 146 \\
& Lisansüstü & 26 & Lisansüstü & 32 \\
\hline Eğitim Kademesi & İlkokul & 50 & İlkokul & 62 \\
& Ortaokul & 63 & Ortaokul & 70 \\
& Lise & 46 & Lise & 46 \\
\hline Mesleki Kıdem (Yıl) & $1-5$ & 18 & $1-5$ & 24 \\
& $6-10$ & 62 & $6-10$ & 74 \\
& $11-15$ & 47 & $11-15$ & 53 \\
& $16-20$ & 19 & $16-20$ & 19 \\
& 21 ve üzeri & 13 & 21 ve üzeri & 8 \\
\hline Okul Müdürü İle Çalışma & $1-2$ & 84 & $1-2$ & 86 \\
Süresi (Yıl) & $3-5$ & 62 & $3-5$ & 62 \\
& $6-7$ & 8 & $6-7$ & 25 \\
& $8-10$ & 5 & $8-10$ & 5 \\
\hline
\end{tabular}

\section{Veri Analizi}

LGÖ'nün geçerlik ve güvenirliği nicel araştırma yaklaşımı kullanılarak tarama modeli ile desenlenmiştir. Araştırma verisinin toplanabilmesi için öncelikle Etik Komisyon izni, ardından yasal izin belgeleri alınmıştır. İzin süreci sonunda veri toplama sürecine geçilmiştir. Veriler internet ortamında araştırmaya katılmaya gönüllü olan öğretmenlerden toplanmıştır. Veri toplama süreci 2020 öğretim yılının Bahar döneminde toplanmıştır. LGÖ için gönüllü 185 katılımcı öğretmene online form 
uygulanmıştır. Toplanan ölçekler incelendiğinde 26'sının analiz için uygun olmadığı tespit edilerek elenmiştir. Geriye kalan analize uygun 159 ölçek üzerinde açımlayıcı faktör analizi (AFA) gerçekleştirilmiştir.

Ayrıca 178 farklı öğretmenden toplanan veriler ile de doğrulayıcı faktör analizi (DFA) gerçekleştirilmiştir. AFA için faktör sayısı tespitinde ölçüt öz-değerin 1'den büyük olmasıdır. Bununla birlikte yamaç birikinti grafiğindeki dik inişler ile birlikte değerlendirme yapılmıştır. Madde faktör yük değeri 0.40 ve üzeri olanlar uygun görülerek madde seçimi yapılmıştır. AFA SPSS 20.0 aracılığıyla gerçekleştirilmiştir. AFA faktör uygunluğu DFA ile test edilmiştir. Literatürde kabul edilen uyum iyiliği değer aralıkları çerçevesinde DFA bulguları değerlendirilmiştir. Ki-kare değerinin serbestlik derecesine oranının 5 'ten küçük olması ölçüt olarak alınmıştır. Alanyazında daha büyük örneklemler için bu değerin 3 'ten küçük olmasının "mükemmel uyumu" gösterdiği söylenmiştir (Kline, 2005). LISREL 8.70 kullanılarak DFA analizileri gerçekleştirilen LGÖ'nün güvenilirliğini belirlemek için ise Cronbach-Alfa, Spearman-Brown, Guttman ve test tekrar test iç tutarlılık katsayılarından faydalanılmıştır.

\section{Bulgular}

\section{LGÖ’nün Geçerliğine İlişkin Bulgular}

Araştırmanın birinci grubuna ait verilere üzerinde AFA uygulanmıştır. Verilerin AFA için gerekli varsayımları sağlayıp sağlamadığını tespit edebilmek amaciyla Kaiser-Meyer-Olkin (KMO) ve Bartlett Küresellik testi yapılmıştır. Araştırma örneklemerinin yeterli olup olmaması durumunda ölçüt olarak kullanılan KMO'nun 0.50'nin üstünde bir değere sahip olmalıdır. KMO'nun değerinin artması örneklemin faktör analizi için o derece yeterli olduğunun göstergesidir. Ayrıca, 0.90 üzerinde bir değere sahip olması ise "mükemmel" olarak değerlendirilmektedir. Araştırma değişkenleri arasındaki ilişki seviyesini ifade ederken kullanılan Bartlett Küresellik testinde yüksek düzeyde ilişkilerin tespit edilmesi ise örneklemin analize uygunluğunu ifade etmektedir (Kalayc1, 2014). Araştırmada KMO değeri .96 ve Bartlett Küresellik Testi de istatistiki açıdan anlamlı çımıştır ( $\chi 2=3646,199$, $p<.001)$. Bu bulgular ışı̆̆ında örneklemin faktör analizi için uygun 
olduğunun yorumu yapılabilir (Şencan, 2005). Varsayımların karşılanmasına dayalı olarak LGÖ’nün yapı geçerliğini değerlendirebilmek amaciyla yapılan AFA bulgularıyla maddelerin toplam korelasyon ve faktör yük değerleri Tablo 2' de sunulmuştur.

Tablo 2. LGÖ'ye Ait Madde Toplam Korelasyon ve Faktör Yük Değerleri

\begin{tabular}{|c|c|c|c|}
\hline & & $\begin{array}{l}\text { Madde Toplam } \\
\text { Korelasyon } \\
\text { Değeri }\end{array}$ & $\begin{array}{c}\text { Faktör Yük } \\
\text { Değerleri }\end{array}$ \\
\hline \multicolumn{4}{|c|}{ Madde } \\
\hline 12 & Davranışlarıyla samimidir. & .911 & .921 \\
\hline 2 & Davranışlarıyla tutarlıdır. & .882 & .894 \\
\hline 9 & Okulda güvene dayalı bir iklim oluşturur. & .873 & .887 \\
\hline 16 & Verdiği sözleri tutar. & .871 & .885 \\
\hline 19 & Söylemi ile beden ili uygunluk gösterir. & .860 & .876 \\
\hline 10 & Çalışanlarının emeğine saygılıdır. & .858 & .874 \\
\hline 14 & Çalışanların tercihlerine saygılıdır. & .857 & .873 \\
\hline 6 & Açık sözlüdür. & .856 & .871 \\
\hline 18 & Çalışanlarına güvenir. & .851 & .868 \\
\hline 11 & Kurumda adil görev dağılımı yapar. & .850 & .866 \\
\hline 20 & Çalışmalarıyla aldığı maaşı hak eder. & .846 & .864 \\
\hline 15 & $\begin{array}{l}\text { Kişisel çıkarları için çalışanlarını asla } \\
\text { suiistimal etmez. }\end{array}$ & .844 & .861 \\
\hline 17 & $\begin{array}{l}\text { Sorun ve problem durumunda çalışanlarına } \\
\text { rehberlik eder. }\end{array}$ & .843 & .861 \\
\hline 4 & Herkese karşı adaletli davranır. & .845 & .860 \\
\hline 1 & Davranışları ile etik ilkelere bağlıdır. & .825 & .842 \\
\hline 7 & Bireysel gelişimimizi önemser. & .811 & .831 \\
\hline 5 & Yalan söylemez. & .808 & .827 \\
\hline 3 & Farklı görüşlere saygı gösterir. & .784 & .805 \\
\hline 8 & $\begin{array}{l}\text { Kişisel bilgilerimi iznim olmadan üçüncü } \\
\text { kişilerle paylaşmaz. }\end{array}$ & .760 & .783 \\
\hline 13 & Ulaş1labilirdir. & .728 & .752 \\
\hline
\end{tabular}

Tablo 2'ye göre LGÖ'de ki maddelerin madde toplam korelasyonlarının .73 ile .91 arasında değer aldığı görülmektedir. Yapılan analizler sonucunda LGÖ'nün tüm maddeleri ayırt edici özellikte olmakla birlikte toplam varyansın \% 73'ünü açıklamaktadır. Gorsuch (1974) toplam varyans yüzdesinin faktör yapısının gücünü açıkladığını belirtirken (akt. Çokluk vd., 2016), Büyüköztürk (2008) ise tek faktör 
yapılı ölçeklerde açıklanan varyansın \%30'dan yüksek olması gerektiğini ifade etmiştir. 20 maddeden oluşan LGÖ'nün öz değeri 14.65'tir. LGÖ'de yer alan maddelerin.75 ile .92 arasında factor yük değerlerine sahipken bu değerlerin .30 üzerinde olması literatürde kabul edilebilir bir ölçüt olarak değerlendirilmektedir (Field, 2005). Bu bulgular ışında LGÖ'ye ait yamaç-birikinti grafiği ise Şekil 1'de sunulmaktadır.

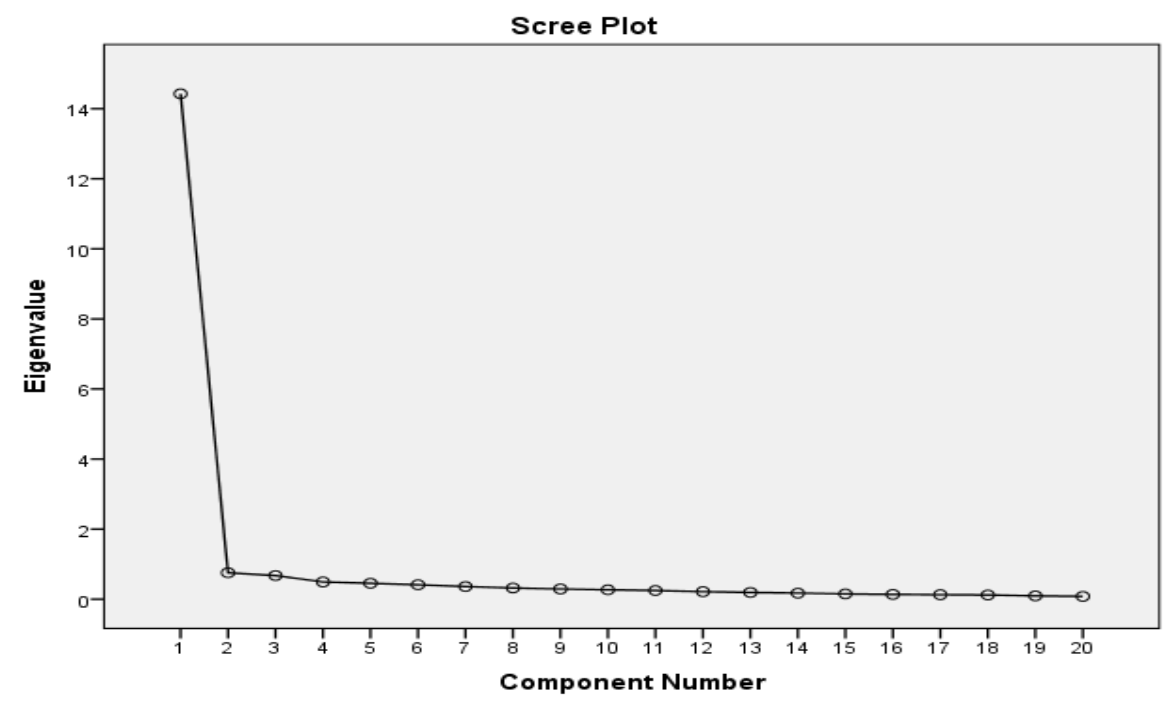

Şekil 1. LGÖ'ye ilişkin yamaç-birikinti grafiği

Şekil 1'e bakıldığında, Y'den X eksenine iniş eğrileri olduğu görülmektedir. Grafikte bulunan noktalar arasındaki eğim aralıkları varyansa olan katkıları ifade etmektedir. Her iki nokta arasındaki aralık ise bir faktörü açıklar. LGÖ’ye ilişkin yamaç birikinti grafiğinde ikinci noktadan sonra eğimin düze yakın bir çizgide ilerlediği izlemektedir. Bu da varyans üstündeki etki büyüklüğünün gitgide azaldığını açıklar. Bu yorumdan yola çıkarak ölçeğin tek faktörlü bir yapıya sahip olduğu ifade edilebilir. LGÖ'nün geçerliğinin değerlendirilebilmesi amacıyla 178 kişiden meydana gelen yeni bir çalışma grubundan tekrar veri toplanmış ve veri seti üzerinde DFA yapılmıştır. LGÖ'nün DFA sonuçları Tablo 3'de sunulmuştur. 
Tablo 3. Lidere Güven Ölçeğine ait DFA Sonuçları

\begin{tabular}{lccc}
\hline Faktör/Madde & t-değeri & $\begin{array}{c}\text { Standartlaştırılmış } \\
\text { Yükler }\end{array}$ & $\mathbf{R 2}$ \\
\hline 1 & 12.44 & 0.78 & 0.62 \\
2 & 13.67 & 0.84 & 0.70 \\
3 & 10.64 & 0.70 & 0.59 \\
4 & 12.84 & 0.80 & 0.64 \\
5 & 11.44 & 0.74 & 0.55 \\
6 & 12.60 & 0.79 & 0.63 \\
7 & 11.36 & 0.74 & 0.54 \\
8 & 10.80 & 0.71 & 0.50 \\
9 & 14.01 & 0.85 & 0.72 \\
10 & 12.62 & 0.79 & 0.63 \\
11 & 12.84 & 0.80 & 0.64 \\
12 & 14.95 & 0.88 & 0.78 \\
13 & 9.45 & 0.64 & 0.61 \\
14 & 12.62 & 0.79 & 0.63 \\
15 & 12.50 & 0.79 & 0.62 \\
16 & 14.19 & 0.86 & 0.73 \\
17 & 13.96 & 0.82 & 0.68 \\
18 & 13.26 & 0.82 & 0.67 \\
19 & 13.67 & 0.83 & 0.69 \\
20 & 12.93 & 0.81 & 0.65 \\
\hline
\end{tabular}

Tablo 3'de görüldüğü üzere de gözlenen değişkeni gizil değişkenlerin açıklama durumlarına ilişkin $t$ değerleri anlamlıdır $(t>2.56, p<0.01)$. Ayrıca standartlaştırılmış yüklere bakıldığında genel olarak her bir madde ile boyutu arasında yüksek düzeyde ilişki olduğu tespit edilmiştir $(r>0.67, p<0,01)$. LGÖ'ye ait geçerlik katsayıları incelendiğinde, ölçeğin geçerli olduğu sonucuna varılmıştır $(r>0.30)$. LGÖ'ye ait path diyagramı Şekil 2'de sunulmaktadır.

Şekil 2'de path diyagramı görülen LGÖ'ye ait serbestlik derecesi (sd) 170 , ki-kare derecesi 369.89 ve $\chi 2 / \mathrm{sd}$ oran1 ise 2.12 bulunmuştur. Schermelleh-Engel vd. (2003), iyi düzeyde kurgulanan bir modelin $\chi 2 / s d$ oranının 3.0'ın altında değer alması gerektiğini ifade etmişlerdir. Modelin uyum iyiliği değerlerinden RMSEA değeri incelendiğinde ise .072 olarak bulunmuş olup kabul edilebilir bir model için bu değerin.08'in altında olması gerekmektedir. LGÖ'ye ait modelin kabul sınırlarında değer aldığı ifade edilebilir. Diğer taraftan DFA sonucu hesaplanan uyum iyiliği değerleri ise Tablo 4'te sunulmuştur. 


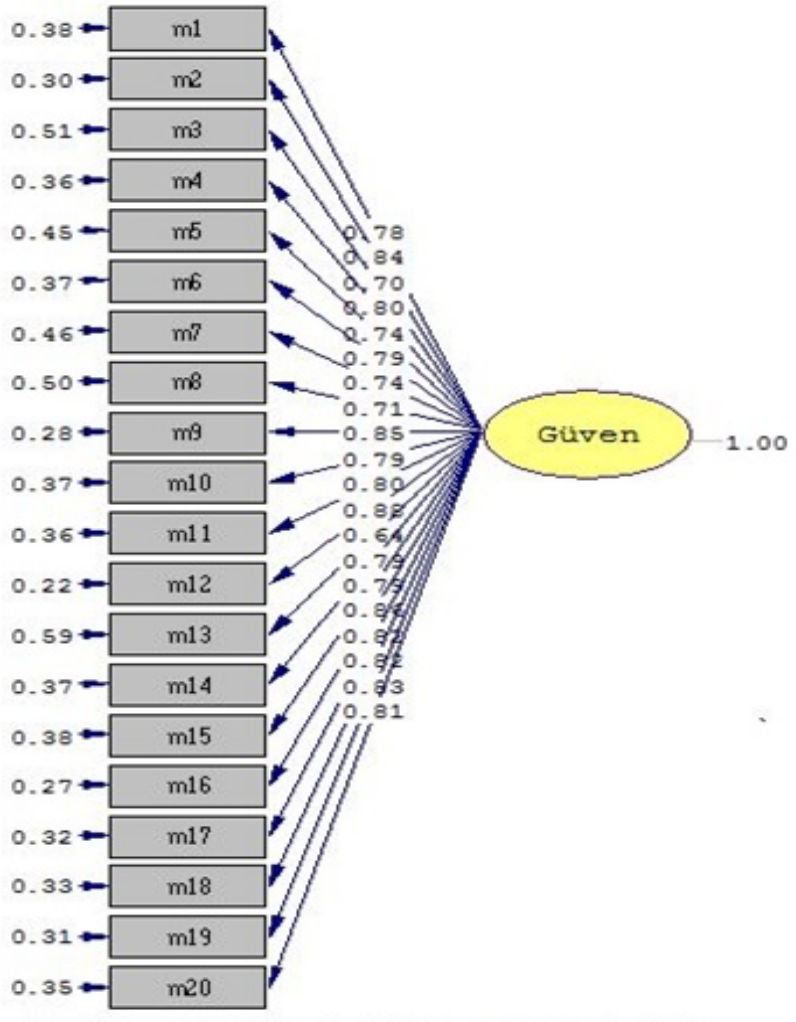

Chi-Square $=369.89, d f=170, \quad P-v a l u e=0.00000$, RMSEA $=0.072$

\section{Şekil 2. LGÖ'ye Ait Path Diyagramı}

Tablo 4. Doğrulayıcı Faktör Analizi Uyum Değerleri

\begin{tabular}{lccc}
\hline $\begin{array}{l}\text { Uyum } \\
\text { indeksleri }\end{array}$ & LGÖ & Kabul Edilebilir Uyum & Mükemmel Uyum \\
\hline$\chi 2 / s d$ & 2.12 & $2 \leq \chi 2 / \mathrm{sd} \leq 3$ & $0 \leq \chi 2 / \mathrm{sd} \leq 2$ \\
RMSEA & .072 & $.05 \leq \mathrm{RMSEA} \leq .08$ & $.00 \leq \mathrm{RMSEA} \leq .05$ \\
AGFI & .85 & $.85 \leq \mathrm{AGFI}<.90$ & $.90 \leq \mathrm{AGFI} \leq 1.00$ \\
NFI & .97 & $.90 \leq \mathrm{NFI} \leq .95$ & $.95 \leq \mathrm{NFI} \leq 1.00$ \\
CFI & .99 & $.90 \leq \mathrm{CFI} \leq .95$ & $.95 \leq \mathrm{CFI} \leq 1.00$ \\
IFI & .99 & $.90 \leq \mathrm{IFI} \leq .95$ & $.95 \leq \mathrm{IFI} \leq 1.00$ \\
GFI & .90 & $.90 \leq \mathrm{GFI}<.95$ & $.95 \leq \mathrm{GFI} \leq 1.00$ \\
\hline
\end{tabular}

Kaynak: Schermelleh, E. K., ve Moosbrugger, H. (2003). Evaluating the fit of structural equation models: Tests of significance and descriptive goodness of fit measures. Methods of Psychological Research Online, 8(2), 23-74. 
Tablo 4'te görüldüğü üzere, LGÖ'nün $\chi 2$ /sd (2.12), RMSEA (0.72), GFI (0.90) ve AGFI (0.85) değerleri kabul edilebilir uyum; NFI (0.97), CFI (0.99) ve IFI (0.99) değerleri mükemmel uyum göstermektedir. Lidere güven ölçeğinin DFA verilerinin yorumlanmasında Schermelleh ve Moosbrugger'in (2003) referans uyum ölçütleri kriter alınmıştır. Elde edilen değerlere göre LGÖ'nün tek faktörlü yapısı doğrulanmaktadır.

\section{LGÖ’nün Güvenirliğe İlişkin Bulgular}

LGÖ’nün güvenirliğinin belirlenmesinde Cronbach Alfa, SpearmanBrown, Guttman ve test tekrar test iç tutarlılık katsayıları incelenmiştir. Sonuçlar, Tablo 5'te sunulmuştur.

Tablo 5. LGÖ'nün İç Tutarlılık Katsayıları

\begin{tabular}{lcccc}
\hline & $\begin{array}{c}\text { Cronbach } \\
\text { Alfa }\end{array}$ & $\begin{array}{c}\text { Spearman- } \\
\text { Brown }\end{array}$ & Guttman & $\begin{array}{c}\text { Test Tekrar } \\
\text { Test }\end{array}$ \\
\hline Lidere Güven & .98 & .96 & .96 & .95 \\
\hline
\end{tabular}

Tablo 5'ten izlenebileceği gibi LGÖ'nün Cronbach Alfa katsayısı .98, Spearman-Brown katsay1s1 .96, Guttman katsay1sı .96 ve test tekrar test katsayısı .95 olarak hesaplanmıştır. Bu bulgular ışı̆̆ında LGÖ'nün iç tutarlılığı yüksek bir veri toplama aracı olduğu söylenebilir.

\section{Tartışma, Sonuç ve Öneriler}

$\mathrm{Bu}$ çalışma eğitim yönetiminde son yıllarda giderek artan önemiyle ön plana çıkan güven olgusu üzerinde odaklanarak öğretmen algısına göre “Lidere Güven Ölçeği-LGÖ” geliştirilmesini amaçlamıştır. Bu kapsamda iki farklı gruptan veri toplanmıştır. Veri setleri üzerinde geçerlik ve güvenirlik analizleri yapılmıştır. Açımlayıcı faktör analizi (AFA) uygun dönüşs sağlanan 159 ölçek üzerinde gerçekleştirilmiştir. Ayrıca 178 farklı öğretmenden dönüş sağlanan veriler üzerinden de doğrulayıcı faktör analizi (DFA) yapılmıştır.

Araştırmada elde edilen bulgular ışında LGÖ’n nün tek boyutlu yüksek düzeyde güvenilir bir ölçme aracı olduğu ortaya konulmuştur. Ulaşılan bu sonuç Yılmaz (2006) tarafından geçerlik ve güvenirlik çalışması 
yapılan Güven Ölçeği'nin alt boyutu olan 7 maddelik Yöneticiye Güven Ölçeği ve Rich'in (1997) pazarlama yöneticileri için geliştirmiş olduğu Lidere Güven Ölçeği'nde sonuçlarıyla uyumludur. Yılmaz (2006) tarafından geçerlik ve güvenirlik çalışması yapılan Güven Ölçeği'nin alt boyutu olan 7 maddelik Yöneticiye Güven Ölçeği ve Rich'in (1997) geliştirdiği Lidere Güven Ölçeği Türkiye'deki gerçekleştirilen araştırmalarda veri toplama aracı olarak kullanıldığı görülmüştür (Doğan, 2019; Meral, 2015; Yangın, 2015; Yılmaz, 2019). Literatürdeki daha önce yapılan çalışmalar ile bu çalışmanın güvenirlik sonuçları birlikte değerlendirildiğinde eğitim örgütleri için geliştirilen LGÖ'nün öğretmen algılarına göre lidere güven odaklı araştırmalarda kullanılmaya elverişli olduğu sonucuna varılmıştır.

AFA ile LGÖ'nün tek faktörlü olduğu ortaya konulmuştur. LGÖ, varyansın \%73'ünü açıklamıştır. Doğrulayıcı faktör analizi sonuçları da modele ait uyum iyiliği değerlerinin "mükemmel uyum" gösterdiğini ortaya koymaktadır. Türkçe alanyazın taramalarında, öğretmen algılarına göre okul müdürlerinin lidere güven davranışlarını belirlemeye yönelik uygun ölçme araçlarının yeterli olmamasına karşın yurt dışında Rich (1997) tarafından pazarlama yöneticileri geliştirilmiş olan lidere güven ölçeğinin AFA sonucunda tek faktör yapısına sahip olduğu görülmüştür. Bu bulgular LGÖ'nün yapı geçerliliğine ilişkin bulguları ile uyum göstermektedir. LGÖ'ye ait tüm maddelerin ayırt edicilik katsayılarının de yüksek olduğu görülmüştür. LGÖ'nün iç tutarlılık katsayılarıyla da yüksek düzeyde güvenilir olduğu değerlendirilmesi yapılmıştır. Tüm bu sonuçlardan yola çıkarak LGÖ'nün Türkiye'deki okullarda okul yöneticilerinin lidere güven davranışlarını tespit etmek için geçerli, elverişli ve güvenilir bir veri toplama aracı olduğu ifade edilebilir.

Bununla birlikte LGÖ'nün daha fazla sayıda örneklem grubundan elde edilecek veriler ışığında geçerlik ve güvenirliklerinin değerlendirilmesiyle alana katkı sağlanabilir. $\mathrm{Bu}$ araştırma için veriler öğretmen örnekleminden sağlanmıştır. Yapılacak diğer araştırmalar için okul yöneticilerine uygulama yapılarak daha üst kademelerde görev yapmakta olan lider eğitim yöneticiler adına LGÖ'nün geçerlik ve güvenirliği çeşitli bağlamlarda değerlendirilebilir. 
EXTENDED ABSTRACT

\title{
Trust in Leaders Scale Development for Educational Organizations: A Validity and Reliability Study
}

\author{
Gamze Tuti- Murat Özdemir \\ MONE- Hacettepe University
}

From past to present, leadership styles of managers have been a criterion for organizational success or failure, and their relationship with many different variables has been investigated. One of these variables is trust, which is one of the basic components of leadership. In terms of educational organizations, trust in the leader expresses teachers' perceptions of trust in their administrators who are leaders in their schools. The demonstration of the efforts of the leader to create an environment based on trust within the organization are the cornerstone of organizational success and increase in efficiency (Kovač \& Jesenko, 2010) supports this importance. In line with this importance, when looking at the scales used in the studies conducted, it is seen that the 7-item Trust in the Administrator Scale, the sub-dimension of the Trust Scale, developed by Tschannen-Moran (2003) and whose validity and reliability study was conducted by Yilmaz (2006), and the Trust in Leader Scale developed for marketing managers by Rich (1997) are used. However, a reliable and valid measurement tool developed to determine teachers' perceptions of trust in school administrators has not been encountered in the literature. It is thought that with TLS, important contributions will be made to this deficiency in the field. Based on this gap in the literature, the purpose of the study is to carry out the validity and reliability studies of the "Trust in Leader Scale" (TLS) according to teachers' opinions. To that end, answers to the following questions were sought in the study;

1. Is TLS a valid data collection tool?

2. Is TLS a reliable data collection tool?

The validity and reliability of the TLS were evaluated with a quantitative approach. Descriptive survey design was used in the research. The data obtained in the study were analyzed via quantitative techniques. Information about the participants, data tools and analysis process of the research is given in this section. 
Data were collected consecutively from two different study groups within the scope of the research. Participants were selected by convenience sampling. This sample type is a sample that the researcher can access easily. In the first study group of the study, there were 159 teachers working in the 2019-2020 academic year, while there were 178 teachers in the second study group. A quantitative approach was used to calculate the validity and reliability of TLS. The data obtained out of the research which had a survey design were analyzed through quantitative methods. In order to collect research data, first the Ethics Committee Approval and then the legal permission documents were obtained. TLS was administered to 159 teachers who voluntarily participated in the study by the researcher as an online form. Exploratory factor analysis (EFA) was performed on 159 scales. EFA factor fit was tested by CFA. In addition, confirmatory factor analysis (CFA) was conducted with data collected from 178 different teachers. In the evaluation of the analysis results obtained as a result of CFA, some goodness of fit criteria accepted in the literature were used. Cronbach-Alfa, SpearmanBrown, Guttman, and test-retest internal consistency coefficients were benefited to determine the reliability of TLS.

EFA was performed on the data set of the first group of the study. In this context, Kaiser-Meyer-Olkin (KMO) and Bartlett Sphericity tests were applied to determine whether the data set provided the assumptions required for EFA. In the study, $\mathrm{KMO}$ value was found to be .96 and Bartlett's Test of Sphericity was statistically significant $(\chi 2=3646,199, \mathrm{p}<.001)$. In order to evaluate the construct validity of TLS, EFA item-total correlation values were calculated in order to determine the discrimination of items. It is seen that the item-total correlations of the items in the TLS vary between .73 and .91. As a result of the analysis, it was determined that all the items in the scale had distinctive features. The total variance explained by TLS is $73 \%$. Eigenvalue (Total $=14.65$ ) and scree plot indicators also support the conclusion that the scale has a single factor structure. In order to evaluate the validity of TLS, data was collected again from a new study group consisting of 178 people and CFA was performed on the data set. The chisquare degree is 369.89 and the degree of freedom is 170 in the path diagram of the TLS. The ratio of chi-square to degrees of freedom $\left(\chi^{2} / \mathrm{df}\right)$ was calculated as $2.12(\mathrm{p}<.05)$. The fact that this value is below 3.0 is interpreted as the theoretical model has a good level of fit (Schermelleh-Engel, Moosbrugger, \& Müller, 2003). The RMSEA value for the CFA model was 
calculated as .072 . The goodness of fit values calculated as a result of the CFA of the TLS are $\chi 2$ / df (2.12), RMSEA (0.72), GFI (0.90) and AGFI (0.85) values show acceptable fit; NFI (0.97), CFI (0.99) and IFI (0.99) values show perfect fit. In the reliability analysis of TLS, the Cronbach Alpha coefficient was calculated as .98, the Spearman-Brown coefficient as .96, the Guttman coefficient as .96, and the test-retest coefficient as .95 . Considering this result, it can be stated that the TLS is a data collection tool with high internal consistency.

The findings obtained in the study showed that TLS is a highly reliable data collection tool at the one-dimensional total score level. This finding is in line with the findings of 7-item Trust in Leader Scale which is a subdimension of the Trust Scale, whose validity and reliability study was conducted by Yilmaz (2006) and Trust in the Leader Scale developed by Rich (1997) for marketing managers. Previously, 7-point Trust in Leader Scale, a sub-dimension of the Trust Scale, whose validity and reliability calculated by Yilmaz (2006) or Trust in the Leader Scale developed by Rich (1997) were used as a data collection tool in the studies conducted in Turkey (Doğan, 2019; Yangın, 2015; Yılmaz, 2019; Meral, 2015). When the research findings and the reliability results obtained in previous studies were evaluated as a whole, it was concluded that the TLS was suitable for use in research based on trust in the leader according to the perceptions of teachers. It has been demonstrated with EFA that TLS has a single factor. TLS explained $73 \%$ of the variance. CFA showed that the goodness of fit values related to the single factor model were at the "perfect fit" level. In the Turkish literature reviews, it was seen that although there weren't adequate measurement tools for determining the trust in leader behaviors according to the perceptions of teachers, the Trust in Leader scale, which was developed for marketing managers abroad by Rich (1997), had a single factor structure as a result of EFA. These findings are consistent with the findings of the TLS regarding the construct validity. It has also been determined that the discrimination power of the items and factors in the TLS is also high. Cronbach's alpha, Guttman, Spearman-Brown, and test-retest internal consistency coefficients showed that TLS was highly reliable. Based on these findings, TLS is concluded to be a valid and reliable data collection tool suitable for use in determining the trust in leader's behavior of teachers at schools in Turkey. 


\section{Kaynakça / References}

Asunakutlu, T. (2002). An evaluation of the factors related to creation of organizational trust. Muğla University Journal of Social Sciences, 9(Autumn), 1-13.

Atar, G. (2009). İlköğretim öğretmenlerinin örgütsel adanmışlıkları ile müdürlerin liderlik davranışlarım algılamaları arasındaki ilişki (İstanbul ili Anadolu Yakası örneği). Maltepe Üniversitesi, Sosyal Bilimler Enstitüsü, İstanbul.

Baier, A. (1985). Postures of the mind: Essays on mind and morals: U of Minnesota Press.

Bennis, W. (1995). Thoughts on the essentials of leadership. Mary Parker Follett-Prophet of Management, Harvard Business School Press, Boston, $M A, 177-181$.

Bilgiç, B. (2020). Okul Müdürlerinin liderlik davranışlarının öğretmenlerin psikolojik sermayeleri ile ilişkisi. Yayımlanmamış Yüksek Lisans Tezi. Hacettepe Üniversitesi Eğitim Bilimleri Enstitüsü, Ankara.

Boyacı, A., Karacabey, M. F. ve Bozkuş, K. (2018). Okul yöneticilerinin liderliğinin öğretmenlerin İş doyumuna etkisinde örgütsel güvenin rolü. Kuram ve Uygulamada Ĕ̆itim Yönetimi Dergisi, 24(3), 437-482.

Bozkurt, S., Çoban, Ö. ve Çolakoğlu, M. H. (2018). Örgütsel güven düzeyi ve toksik liderlik davranışları ilişkisinde örgütsel bağlılığın aracı etkisi. Hacettepe Üniversitesi Ĕ̆itim Fakültesi Dergisi, 1, 1-18.

Börü, D., İslamoğlu, G. ve Birsel, M. (2007). Güven: Bir anket geliştirme çalışması. Öneri. Marmara Üniversitesi Sosyal Bilimler Enstitüsü Dergisi, $7(27), 49-59$.

Büssing, A. (2000). Identity and trust trough work in virtual organizations. In Boos, M., Jonas, K.J. and Sassenberg, K. (Eds.), Computer mediated communication in organisations (p.57-72). Göttingen: Hogrefe.

Butler Jr, J. K. (1991). Toward understanding and measuring conditions of trust: Evolution of a conditions of trust inventory. Journal of management, 17(3), 643-663.

Butler Jr, J. K. and Cantrell, R. S. (1984). A behavioral decision theory approach to modeling dyadic trust in superiors and subordinates. Psychological reports, 55(1), 19-28. 
Büyüköztürk, Ş., Çakmak, E. K., Akgün, Ö. E., Karadeniz, Ş. ve Demirel, F. (2008). Bilimsel araştırma yöntemleri (2. Basım). Ankara: Pegem Akademi.

Cansoy, R. ve Parlar, H. (2018). Dağıtılmış liderlik, yöneticiye güven ve okul akademik iyimserliği arasındaki ilişkinin incelenmesi. Kuram ve Uygulamada Egitim Yönetimi Dergisi, 24(1), 1-44.

Cemaloğlu, N. (2007). Okul yöneticilerinin liderlik stilleri ile yıldırma arasındaki ilişki. Hacettepe Üniversitesi Ĕ̆itim Fakültesi Dergisi, 33(33), 77-87.

Cemaloğlu, N. ve Kılınç, A. Ç. (2012). İlköğretim okulu yöneticilerinin etik liderlik davranışları ile öğretmenlerin algıladıkları örgütsel güven ve yıldırma arasındaki ilişki. Eğitim ve Bilim Dergisi, 37(165), 137-151.

Çokluk, Ö., Şekercioğlu, G. ve Büyüköztürk, Ş. (2012). Sosyal bilimler için çok değişkenli istatistik: SPSS ve LISREL uygulamaları. Ankara: Pegem Akademi.

Çelik, V. (2003). Eğitimsel liderlik. PegemA Yayıncllık, Ankara.

Dede, N. P. (2019). Dönüşümcü liderlik ve örgütsel bağlllık ilişkisinde lidere olan güvenin aracı rolü üzerine bir araştırma. Business ve Management Studies: An International Journal, 7(4), 1923-1943.

Demircan, N. ve Ceylan, A. (2003). Örgütsel güven kavramı: Nedenleri ve sonuçları. Yönetim ve Ekonomi: Celal Bayar Üniversitesi Iktisadi ve İdari Bilimler Fakültesi Dergisi, 10(2), 139-150.

Demirtaş, H. ve Demirbilek, N. (2019). Okul müdürlerinin kayırmacı davranışlarının öğretmenlerin örgütsel adalet algıları ile müdüre güvene etkisi. Bingöl Üniversitesi Sosyal Bilimler Enstitüsü Dergisi, 9(17), 111-142.

Dirks, K. T. and Ferrin, D. L. (2001). The role of trust in organizational settings. Organization science, 12(4), 450-467.

Driscoll, J. W. (1978). Trust and participation in organizational decision making as predictors of satisfaction. Academy of management journal, 21(1), 44-56.

Doğan, H. (2019). Yönetici rolleri ve etkileme taktikleri ile öğretmenlerin yöneticiye güveni arasındaki ilişkiler. Doktora Tezi. Pamukkale Üniversitesi, Eğitim Bilimleri Enstitüsü, Denizli. 
Duman, Ş. (2018). Ortaöğretim öğretmenlerinde psikolojik güçlendirmenin yordayıclar olarak yapısal güçlendirme, yöneticiye güven ve lider-üye etkileşimi. (Yayımlanmamış Doktora Tezi). Gazi Üniversitesi Eğitim Bilimleri Enstitüsü, Ankara.

Eraslan, L. (2004). Liderlikte post-modern bir paradigma: dönüşümcü liderlik. Uluslararasi Insan Bilimleri Dergisi, 1(1), 1-32.

Erden, A. (2007). Ankara ve Lefkoşa okul yöneticilerinin ve öğretmenlerinin örgütsel güvene ilişkin görüşleri. (Yayımlanmamış doktora tezi). Ankara Üniversitesi Eğitim Bilimleri Enstitüsü, Ankara.

Ertuğrul, A. ve Töremen, F. (2017). Okul yöneticileri liderlik stillerinin okul iklimi üzerindeki etkisi: Gaziantep orta öğretim okullarında bir uygulama. Ekonomi ve Sosyal Araştırmalar Dergisi, 4(7), 48-82.

Ertürk, R. (2019). Okul müdürlerinin etik liderlik davranışları, öğretmenlerin okul müdürüne güven algıları ve örgütsel bağlllıklarının çeşitli değişkenler açısından incelenmesi. İnönü Üniversitesi Eğitim Fakültesi Dergisi, 20(1), 119-135.

Field, A. (2005). Discovering Statistics Using SPSS. 2nd Edition, SAGE, London.

Greenfield, P. M. (1991). Language, tools and brain: The ontogeny and phylogeny of hierarchically organized sequential behavior. Behavioral and brain sciences, 14(4), 531-551.

Gümüşeli, A. İ. (2001). Çağdaş okul müdürünün liderlik alanları. Kuram ve Uygulamada Egitim Yönetimi, 7(4), 531-548.

Güven, Ç. (2017). Algilanan liderlik tarzlarının çalışan sesine etkisinde örgütsel güvenin rolü ve bir araştırma. Yüksek Lisans Tezi. Marmara Üniversitesi, Sosyal Bilimler Enstitüsü, İstanbul.

Holmes, G. and Rempel, K. (1989). Trust in close relationships' in hendrick, Clyde (ed). Close relationships. In: Newbury Park, CA: Sage,187-222.

Hoy, W. and Kupersmith, W. (1985). The meaning and measure of faculty trust. Educational and psychological research, 5(1), 1-10.

Hoy, W. K., Tarter, C. J. and Hoy, A. W. (2006). Academic optimism of schools: A force for student achievement. American Educational Research Journal, 43(3), 425-446.

Hoy, W. K. and Tschannen-Moran, M. (1999). Five faces of trust: An empirical confirmation in urban elementary schools. Journal of School leadership, 9(3), 184-208. 
Hubbell, A. P. and Chory-Assad, R. M. (2005). Motivating factors: Perceptions of justice and their relationship with managerial and organizational trust. Communication studies, 56(1), 47-70.

Kalaycı, Ş. (2014). SPSS uygulamalı çok değiş̧kenli istatistik. Asil Yayın Dağıtım, Ankara.

Karadağ, E., Başaran, A. ve Korkmaz, T. (2009). İlköğretim okulu öğretmenlerinin algiladiklari liderlik biçimleri ile iş doyumlari arasindaki ilişki. Balıkesir Üniversitesi Sosyal Bilimler Enstitüsü Dergisi, 12(21), 32-45.

Koç, H. ve Yazıcıoğlu, İ. (2011). Word and thought: The relation between the trust in manager and work satisfaction: Comparison between the public and private sectors. Doğuş Üniversitesi Dergisi, 12(1), 46-57.

Korkmaz, O. (2017). Otantik liderlik ve örgütsel güven. The Journal of Academic Social Science Studies, 58, 437-454.

Mirza, M. and Redzuan, M.r. (2012). The relationship between teacher's organizational trust and organizational commitment in primary schools. Life Science Journal-Acta Zhengzhou University Overseas Edition, 9(3), 1372-1376.

Uslu, O., Özsoy, E. ve Ardıç, K. (2018). Liderlik Tarzları ve Lidere Güven Arasındaki İlişki. In ICPESS (International Congress on Politic, Economic and Social Studies) (No. 4).

Özcan, D. (2019). Okul müdürlerinin liderliği ile öğretmenlerin mesleki tükenmişliklerinin bazi değişkenler açisindan incelenmesi. Yüksek Lisans Tezi. Hacettepe Üniversitesi, Eğitim Bilimleri Enstitüsü, Ankara.

Özdaşlı, K. ve Yücel, S. (2010). Yöneticiye bağlllıkta yöneticiye güvenin etkisi: yapısal eşitlik modeli ile bir analiz. Süleyman Demirel Üniversitesi, Sosyal Bilimler Enstitüsü Dergisi, 11, 67-83.

Paşa, Ö. (2015). Öğretmenlerin yöneticiye güven düzeyleri ve okul yöneticisi tarafindan sergilenen etik liderlik davranışlarının örgütsel sessizlik üzerindeki etkisi. Yayınlanmamış Yüksek Lisans Tezi. Mevlana Üniversitesi Sosyal Bilimler Enstitüsü, Konya.

Perry, R. W. and Mankin, L. D. (2007). Organizational trust, trust in the chief executive and work satisfaction. Public Personnel Management, 36(2), 165-179.

Pillai, R., Schriesheim, C. A. and Williams, E. S. (1999). Fairness perceptions and trust as mediators for transformational and transactional leadership: A two-sample study. Journal of management, 25(6), 897-933. 
Polat, S. (2007). Ortaöğretim öğretmenlerinin örgütsel adalet algıları, örgütsel güven düzeyleri ile örgütsel vatandaşlık davranışları arasındaki ilişki. Yayımlanmamış Doktora Tezi. Kocaeli Üniversitesi Sosyal Bilimler Enstitüsü, Kocaeli.

Rich, G. A. (1997). The sales manager as a role model: Effects on trust, job satisfaction, and performance of salespeople. Journal of the Academy of Marketing Science, 25(4), 319-328.

Robinson, S. L. (1996). Trust and breach of the psychological contract. Administrative science quarterly, 41(4), 574-599.

Schermelleh-Engel, K., Moosbrugger, H. and Müller, H. (2003). Evaluating the fit of structural equation models: Tests of significance and descriptive goodness-of-fit measures. Methods of psychological research online, 8(2), 23-74.

Tan, H. H. ve Tan, C. S. (2000). Toward the differentiation of trust in supervisor and trust in organization. Genetic, social, and general psychology monographs, 126(2), 241.

Tschannen-Moran, M. (2003). Transformational leadership and trust. Studies in leading and organizing schools, 2(11), 157-169.

Tschannen-Moran, M. and Hoy, W. K. (1998). Trust in schools: A conceptual and empirical analysis. Journal of Educational Administration, 36, 334352.

Ugar, Y. (2019). Okul müdürlerinin liderlik uygulamalar ile öğretmenlerin motivasyon arasindaki ilişki. Yüksek Lisans Tezi. İstanbul Sabahattin Zaim Üniversitesi, Sosyal Bilimler Enstitüsü, İstanbul.

Whitener, E. M., Brodt, S. E., Korsgaard, M. A. and Werner, J. M. (1998). Managers as initiators of trust: An exchange relationship framework for understanding managerial trustworthy behavior. Academy of management review, 23(3), 513-530.

Yangın, D. (2015). Etkileşim adaleti ve yöneticiye güven ile öğretmenlerin örgütsel sessizlik davranışları arasındaki ilişki. Yayımlanmamış Yüksek Lisans Tezi. On Dokuz Mayıs Üniversitesi, Eğitim Bilimleri Enstitüsü, Samsun.

Yılmaz Fındık, L ve Kavak, Y. (2016). PISA 2012 sonuçlarına göre yönetici liderliği ve okul özerkliğinin öğrenci başarısına etkisi. Hacettepe Üniversitesi Ĕ̆itim Fakültesi Dergisi (H. U. Journal of Education), 32(4), 939-959. 
Yılmaz, G. (2019). Lidere güvenin örgütsel bağhlllk üzerindeki etkisi: Ĕ̆itim sektörü çalışanlarına yönelik ampirik bir çalışma. Yüksek Lisans Tezi. Bahçeşehir Üniversitesi, Sosyal Bilimler Enstitüsü, İstanbul.

Yılmaz, K. (2006). Güven ölçeği geçerlik ve güvenirlik çalışması. Sakarya Üniversitesi Ĕ̆itim Fakültesi Dergisi, 11, 69-80.

Yolaç, S. (2011). Yöneticinin algılanan liderlik tarzı ile yöneticiye duyulan güven arasındaki ilişkide lider üye etkileşiminin rolü. Öneri Dergisi, $9(36), 63-72$.

\section{Kaynakça Bilgisi / Citation Information}

Tuti, G. ve Özdemir, M. (2021). Eğitim örgütleri için Lidere Güven Ölçeğinin geliştirilmesi: Geçerlik ve güvenirlik çalışması. OPUSUluslararası Toplum Araştırmaları Dergisi, 18(Eğitim Bilimleri Özel Say1s1), 4850-4874. DOI: 10.26466/opus.861588. 